\title{
Autophagy is essential for flavopiridol-induced cytotoxicity against MCF-7 breast cancer cells
}

\author{
SHUO WANG $^{1 *}$, KAI WANG $^{2 *}$, HUAIQUAN WANG $^{2}$, JIANKUI HAN ${ }^{3}$ and HUKUI SUN ${ }^{2,3}$ \\ ${ }^{1}$ Nephrology Department; ${ }^{2}$ Nuclear Medicine Department, Central Hospital of Zibo, Zibo, Shandong 255036; \\ ${ }^{3}$ Nuclear Medicine Department, Qilu Hospital, Jinan, Shandong 250012, P.R. China
}

Received May 27, 2017; Accepted September 11, 2017

DOI: $10.3892 / \mathrm{mmr} .2017 .7815$

\begin{abstract}
Flavopiridol (FP) exerts antitumoral effects by triggering tumor cell cycle arrest and cytotoxicity in human breast cancer cell lines. The potent antitumor activity of FP is through its inhibition of cyclin-dependent kinases; however, this may not be the only mechanism of action. The present study aimed to investigate whether FP is able to induce autophagy and to examine the effects of autophagy on cell death in FP-treated MCF-7 human breast cancer cells. MCF-7 cells were treated with either FP alone or FP in combination with chloroquine (CQ). Expression levels of autophagy-related protein LC3B-II and p62/sequestosome 1 (SQSTM1) were used to monitor autophagic flux. MCF-7 cells were transfected with autophagy-related 5 (ATG5) small interfering (si)RNA to block autophagy. Cell viability and cell cycle status were determined. Following incubation with FP, MCF-7 cells exhibited significantly higher autophagy compared with untreated control cells, and the level of autophagy is comparable with cells under rapamycin induction, which was verified by immunodetection of LC3B-II and p62/SQSTM1 expression and inhibition by $\mathrm{CQ}$. The addition of CQ treatment or ATG5-siRNA transfection against autophagy components attenuated the cytotoxic effects of FP treatment of MCF-7 cells. Furthermore, this autophagy inhibition did not impair the FP-induced cell cycle arrest. These results revealed that autophagy may be involved in FP-induced MCF-7 cell death and autophagy inhibition enhanced the tumor cell pro-survival ability. It is possibly that potential autophagy regulatory drugs may be used as a chemotherapy adjuvant.
\end{abstract}

Correspondence to: Dr Hukui Sun, Nuclear Medicine Department, Central Hospital of Zibo, 54 Gongqingtuanxi Road, Zibo, Shandong 255036, P.R. China

E-mail: sunhukui@mail.sdu.edu.cn

*Contributed equally

Abbreviations: CDK, cyclin-dependent kinase; CQ, chloroquine; FP, flavopiridol

Key words: flavopiridol, autophagy, MCF-7, cytotoxicity

\section{Introduction}

Breast cancer is one of the most commonly diagnosed cancers in women worldwide. The incidence rate increases every year, and breast cancer is becoming more prevalent in younger age groups (1). The 5- and 10-year survival rates for metastatic breast cancer are currently estimated at $<25$ and $5-10 \%$, respectively (2). Continued investigations into the role of dysregulated cell cycling in human breast cancer have led to the identification of several therapeutically attractive targets $(3,4)$. Recently, the synergistic effects of autophagy and cyclin-dependent kinase (CDK) inhibitors have been reported in cancer therapy (5). Flavopiridol (FP) is a CDK inhibitor that is known for its activity in arresting cell cycle at the $\mathrm{G}_{1}-\mathrm{S}$ or $\mathrm{G}_{2}-\mathrm{M}$ boundary and in mediating antiproliferative effects by inhibiting multiple CDKs $(6,7)$. In addition, comprehensive studies have demonstrated the antitumoral activity of FP against human tumor cell lines $(4,8,9)$; FP is considered an important ancillary tumor chemotherapy drug for its cytotoxicity in resting cells. In human breast cancer cells, FP may also downregulate the expression of antiapoptosis proteins in the inhibitor of apoptosis (IAP) family and $\mathrm{B}$ cell lymphoma-extra large $\left(\mathrm{Bcl}-\mathrm{X}_{\mathrm{L}}\right)$ and upregulate the expression of proapoptotic $\mathrm{Bcl}-2$-associated $\mathrm{X}$ protein (Bax) to induce cell growth arrest and apoptosis, and these effects are independent of tumor estrogen receptor (ER) status (10-12). However, the potential molecular mechanisms leading to cell apoptosis are unclear.

Autophagy is a catabolic process that regulates the degradation and recycling of organelles and proteins to maintain the general cellular homeostasis (13). Once autophagy is activated, it may either induce tumor cell death (14) or antiapoptotic survival (15). Numerous scientific reports have demonstrated the association between autophagy and cancer cell biologic activities, such as survival, apoptosis and metastasis. Apoptosis activation serves as a potential anticancer strategy by repressing various types of tumor cells $(16,17)$. A previous study demonstrated that significant autophagy flux in FP-treated chronic lymphocytic leukemia (CLL) cells was initiated by FP-induced endoplasmic reticulum stress other than the result of directly inhibition of CDKs. Furthermore, inhibition of autophagy enhances FP cytotoxicity, which indicated that FP-induced autophagy may serve a drug resistance role in CLL cells (18). 
Autophagy and apoptosis were demonstrated to be induced by antitumor drugs in human breast cancer cell lines, such as Paris saponin XA-2 and rapamycin (19). Those two drugs promoted breast cancer cell apoptosis via the Akt/mammalian target of rapamycin signaling pathway, which is also independent of cancer cell ER expression, as evidenced by the caspase activation and cleavage of Poly (ADP-ribose) polymerase. A recent study demonstrated that specific inhibition or small interfering siRNA-mediated silencing of inositol 1,4,5-trisphosphate receptors induced autophagic cell death through compromised bioenergetics and the generation of reactive oxygen species in MCF-7 human breast cancer cells (20). In other human breast tumor cell lines, such as SKBR-3 and MB-468, FP treatment was revealed to reduce the expression levels of the antiapoptotic proteins IAP, Bcl- $\mathrm{x}_{\mathrm{L}}$ and myeloid cell leukemia 1 to induce cell death and enhanced the cytotoxicity of epothilone $\mathrm{B}$, which is impeded by overexpression of Bcl-2 (11). Bcl-2 is a crucial factor involved in the process turning a normal cell into a cancerous one. Other than being an antiapoptotic protein, Bcl-2 also suppresses autophagy by directly targeting beclin 1, a component of the class III phosphoinositide 3-kinase (PI3K) pathway that serves a role in autophagosome formation (21). Although FP-induced apoptosis and autophagy in different types of cancer cells has been well studied, the capacity of FP-induced autophagy in human breast cancer has, to the best of our knowledge, not yet been examined. The present study investigated whether FP treatment was able to induce autophagy in MCF-7 cells and determined the role of autophagy in survival and cell cycle arrest.

\section{Materials and methods}

MCF-7 cells in culture. MCF-7 human breast cancer cells were purchased from Nanjing KeyGen Biotech Co., Ltd. (Nanjing, China) and were grown in RPMI-1640 medium (GIBCO; Thermo Fisher Scientific, Inc., Waltham, MA, USA) supplemented with $10 \%$ fetal bovine serum (HyClone; GE Healthcare, Logan, UT, USA), $0.01 \mathrm{mg} / \mathrm{ml}$ bovine insulin (Sigma-Aldrich; Merck KGaA, Darmstadt, Germany), $100 \mathrm{U} / \mathrm{ml}$ penicillin and $0.1 \mathrm{mg} / \mathrm{ml}$ streptomycin (Beyotime Institute of Biotechnology, Haimen, China) and maintained in an incubator at $37^{\circ} \mathrm{C}$ with $95 \%$ humidity and $5 \% \mathrm{CO}_{2}$.

Western blotting. MCF-7 cells were treated with rapamycin $(5 \mu \mathrm{M})$ or FP $(1 \mu \mathrm{M})$ with or without chloroquine (CQ; $500 \mathrm{nM}$; Sigma-Aldrich; Merck KGaA) for a total of $48 \mathrm{~h}$ at $37^{\circ} \mathrm{C}$, based on a previously published protocol (18). A total of $1 \times 10^{6} \mathrm{MCF}-7$ cells were harvested by scraping the cells from culture plates and collected by centrifugation at $40 \mathrm{xg}$ for $6 \mathrm{~min}$ at $4^{\circ} \mathrm{C}$. Cells were resuspended in $125 \mathrm{mM}$ Tris buffer ( $\mathrm{pH}$ 6.8) and sonicated twice for 10 sec each and lysed using an equal volume of $8 \%$ SDS. Cell extracts were boiled for $10 \mathrm{~min}$ and chilled on ice. Protein concentration was measured using the Bicinchoninic Acid Solution (Sigma-Aldrich; Merck KGaA). The samples (10 $\mu \mathrm{g}$ for each well) were loaded on $10 \%$ SDS-PAGE for separation, and electrophoretically transferred to a nitrocellulose (NC) membrane. Subsequently, membranes were blocked at room temperature for $1 \mathrm{~h}$ in western blocking buffer (Beyotime Institute of Biotechnology). Each membrane was incubated with monoclonal antibodies against autophagy-related protein
LC3B-II, p62/sequestosome 1 (SQSTM1), autophagy-related 5 (ATG5) and GAPDH (cat. no. 66139-1-Ig, 66184-1-Ig, 60061-1-Ig and 60004-1-Ig, respectively; Wuhan Sanying Biotechnology, Wuhan, China) at a dilution of $1: 1,000$, at $4^{\circ} \mathrm{C}$ overnight. Blots were washed with PBS with $0.05 \%$ Tween-20 and incubated with horseradish peroxidase-conjugated secondary antibodies (cat. no. A0216, Beyotime Institute of Biotechnology) at a dilution of 1:1,000, at room temperature for $1 \mathrm{~h}$. Signal intensities were measured using a chemiluminescence Detection System (Pierce; Thermo Fisher Scientific, Inc.). Autoradiograms were scanned with a Gel Doc 1000 Imaging System (Bio-Rad Laboratories, Inc., Hercules, CA, USA). The bi-dimensional optical density of proteins on the films was quantified and analyzed with Molecular Analysis Software (version 1.6.3, Bio-Rad Laboratories, Inc.). GAPDH was used as the internal control for LC3B-II, SQSTM1 and ATG 5 expression analysis.

siRNA experiments. Exponentially growing untreated MCF-7 cells were collected and cultured (2x10 $/$ well in $2 \mathrm{ml})$ for $24 \mathrm{~h}$ before transfection. Plated cells were transfected with $80 \mathrm{pmol}$ of either siRNA against human ATG5 (cat. no. sc-41445; Santa Cruz Biotechnology, Inc., Dallas, Texas, USA) or a negative control siRNA (cat. no. sc-37007; Santa Cruz Biotechnology, Inc.) in $100 \mu \mathrm{l}$ siRNA transfection media and an X-tremeGENE Transfection Reagent (Roche Diagnostics, Basel, Switzerland) $8 \mu \mathrm{l}$ at $37^{\circ} \mathrm{C}$ for $8 \mathrm{~h}$, following the manufacturer's protocol. Two days post-siRNA transfection, cells were treated with FP for $48 \mathrm{~h}$. Following the final incubation, total protein was harvested and subjected to western blot analysis.

Cell viability assay. Cell viability was determined using a Cell Counting kit-8 (CCK-8; Beyotime Institute of Biotechnology). Briefly, cells (5,000 cells/well) were seeded in culture medium in 96 -well plates and incubated at $37^{\circ} \mathrm{C}$ for $24 \mathrm{~h}$ prior to drug treatments. Subsequently, the culture medium was replaced with fresh medium containing either FP $(1 \mu \mathrm{M})$ alone or FP $(1 \mu \mathrm{M})$ with CQ $(0.5 \mu \mathrm{M})$ or CQ $(0.5 \mu \mathrm{M})$ alone and cells were incubated for $48 \mathrm{~h}$ at $37^{\circ} \mathrm{C}$. The control group was treated with $0.2 \%$ DMSO alone. Finally, cells were incubated with complete medium containing $10 \mu \mathrm{lCCK}-8$ solution at $37^{\circ} \mathrm{C}$ for $2 \mathrm{~h}$ and optical density at $450 \mathrm{~nm}$ was measured as the percentage of cells compared with the control group, using a microplate reader. After ATG5 siRNA (80 pmol/100 $\mu \mathrm{l})$ was transfected, cells were divided into three groups: untransfected group, control siRNA group and siRNA ATG5 group. And cells were treated with FP or equal volume PBS. The control group was treated with $0.2 \%$ DMSO. The measurement was the same as above.

Cell cycle analysis. For cell cycle analysis, cells $\left(2 \times 10^{4}\right.$ cells/well) were plated in a 24 -well plate and grown to $60 \%$ confluency. The cells were grown in serum free medium for $24 \mathrm{~h}$ to have limited synchronization. Then, normal MCF-7 cells were treated in complete medium with either FP $(1 \mu \mathrm{M})$ or FP $(1 \mu \mathrm{M})$ with CQ $(0.5 \mu \mathrm{M})$ at $37^{\circ} \mathrm{C}$ for $48 \mathrm{~h}$. siRNA transfected cells were treated with $\mathrm{FP}(1 \mu \mathrm{M})$ alone at the same conditions. Following treatments, cells were harvested by centrifugation at $40 \mathrm{xg}$ for $6 \mathrm{~min}$ at $4^{\circ} \mathrm{C}$ and fixed in cold ethanol $(70 \% \mathrm{v} / \mathrm{v})$ in PBS for at least $2 \mathrm{~h}$ at $4^{\circ} \mathrm{C}$. Fixed cells 
were washed with PBS and stained with a solution containing propidium iodide $(6 \mu \mathrm{M}), 0.5 \%$ Triton $\mathrm{X}-100$ and RNase $(100 \mu \mathrm{g} / \mathrm{ml})$ for $30 \mathrm{~min}$ at room temperature, in the dark. DNA content was analyzed through flow cytometry. The percentage of cells in $\mathrm{G}_{0}-\mathrm{G}_{1}, \mathrm{~S}$ and $\mathrm{G}_{2}-\mathrm{M}$ phases was calculated using MultiCycle Software (version 3.0; Phoenix Flow Systems, San Diego, CA).

Statistical analysis. Data are presented as the mean \pm standard deviation from three experiments. Two-way t-tests were used to analyze the variance in two groups for possible significance. One-way analysis of variance followed Tukey's method was used for multiple comparisons. Statistical analysis was performed using GraphPad Prism Software version 7.00 (GraphPad Software, Inc., La Jolla, CA, USA). P<0.05 was considered to indicate a statistically significant difference.

\section{Results}

MCF-7 cells are susceptible to autophagy induced by FP. As induction of autophagy in human breast cancer cell lines has been fully confirmed including MCF-7 cells (20), it was determined whether MCF-7 cells undergo autophagy with FP during this process (19). MCF-7 cells were incubated for $48 \mathrm{~h}$ with $1 \mu \mathrm{M}$ FP or with $5 \mu \mathrm{M}$ rapamycin (a well-characterized initiator of autophagy). Western blot analysis demonstrated classic autophagy performance of LC3B protein expression in the rapamycin-treated MCF-7 cells, although this was not quantified (Fig. 1A). Western blot analysis also demonstrated that LC3B-II expression was significantly increased in FP-treated cells compared with the control (Fig. 1B; $\mathrm{P}<0.01$ ), which indicated the induction of autophagosome formation by FP incubation.

Verification of autophagy induced by FP. LC3 protein was previously reported to be localized in structures other than autophagosomes in some tissues $(22,23)$; however, immunodetection of LC3 in cytoplasmic granules is not sufficient as an absolute marker to monitor autophagy. Recent guidelines for the use and interpretation of assays for monitoring autophagy recommended using p62/SQSTM1 and LC3B-II turnover to monitor flux (24). CQ is a proteasome inhibitor; it interrupts the autophagy flux by inhibiting lysosome-mediated proteolysis (25). Therefore, the present study analyzed the protein expression levels of both LC3B-II and p62/SQSTM1 (Fig. 2A-C). Western blotting results revealed the expected decrease of p62/SQSTM1 protein expression in FP-treated MCF-7 cells and restored by FP and CQ co-treatment (Fig. 2A and $\mathrm{C}, \mathrm{P}<0.05)$. This could imply that the change in LC3B and p62/SQSTM1 expression levels could be the result of FP-induced autophagy in MCF-7 cells and it was successfully blocked by co-treatment with $\mathrm{CQ}$.

Inhibition of autophagy antagonizes FP cytotoxicity. Co-treatment with FP and CQ significantly antagonizes the cytotoxicity of FP in MCF-7 cells ( $\mathrm{P}<0.05$; Fig. 3A). As CQ is not a specific autophagy inhibitor, it may affect other cellular processes in addition to autophagy. After transfected with siRNA ATG5, the expression of ATG5 was knocked down (Fig. 3B). The expression trend of both LC3B
Table I. Cell cycle effects of autophagy inhibition ${ }^{\mathrm{a}}$ on $\mathrm{MCF}-7$ cells.

\begin{tabular}{lccc}
\hline Treatment & $\mathrm{G}_{0}-\mathrm{G}_{1}(\%)$ & $\mathrm{S}(\%)$ & $\mathrm{G}_{2}-\mathrm{M}(\%)$ \\
\hline Control & $45 \pm 2$ & $26 \pm 3$ & $29 \pm 7$ \\
FP & $61 \pm 5$ & $19 \pm 4$ & $20 \pm 6$ \\
FP + CQ & $63 \pm 9^{\mathrm{b}}$ & $22 \pm 8$ & $15 \pm 2$ \\
FP + ATG5 siRNA & $64 \pm 3^{\mathrm{b}}$ & $20 \pm 3$ & $16 \pm 5$ \\
\hline
\end{tabular}

${ }^{a}$ Autophagy inhibition with either CQ or ATG5 siRNA; the percentage of cells in the $G_{1}$ phase does not exhibit a significant difference compared with FP-treated cells $\left({ }^{b} \mathrm{P}>0.05\right)$. $\mathrm{CQ}$, chloroquine; FP, flavopiridol; siRNA, small interfering.

and p62/SQSTM1 validated that autophagy was blocked after transfection compared with the untransfected cells and control siRNA-transfected cells (Fig. 3B). There was a significantly higher rate in cell survival in ATG5-silenced MCF-7 cells compared with the untransfected and the control siRNA-transfected cells treated with FP (Fig. 3C; $\mathrm{P}<0.01)$.

FP-induced cell cycle arrest is not impaired by autophagy inhibition. Autophagy is generally associated with metabolic activity, including proliferation and cell cycle. It has been proved that FP blocked MCF-7 cells at G1 stage, inhibition of resveratrol-induced autophagy abolished cell cycle arrest by restoring the levels of cyclin A and B to normal levels in glioma cells (26). In the present study, autophagy inhibition by CQ or ATG5 siRNA treatment did not notably impair the $\mathrm{G}_{0}-\mathrm{G}_{1}$ phase of the cell cycle $(\mathrm{P}>0.05$; Table $\mathrm{I})$. These data suggested that FP may have a cell cycle regulation role but this needs to be determined.

\section{Discussion}

CDK inhibition is an important target for breast cancer treatments, which is resistant to endocrine therapy (4). Flavopiridol is a semisynthetic flavonoid that is derived from rohitukine. Significant effort has been made to understand the detailed pathways of FP action (27). Briefly, the mechanisms of antitumoral effects may lie in direct inhibition of CDK expression or activation by binding to the ATP-binding site or by the prevention of CDK phosphorylation, which is overexpressed in many human neoplasias $(28,29)$. However, this does not offer a sufficient explanation as to how FP induces cell death in growth-arrested cancer cells.

An important biochemical mechanism that is involved in FP-induced proapoptotic cell death is autophagy (10). The present study demonstrated that MCF-7 cells expressed crucial components of the autophagy machinery, which may be robustly activated by FP. FP induced aggregation of LC3B-II and decreased p62/SQSTM1 expression levels which was partially abolished by CQ co-treatment and siRNA ATG5 transfection. Autophagy inhibition by CQ resulted in notably higher cell survival rate compared with cells treated with FP alone. Furthermore, this was also confirmed by ATG5 
A
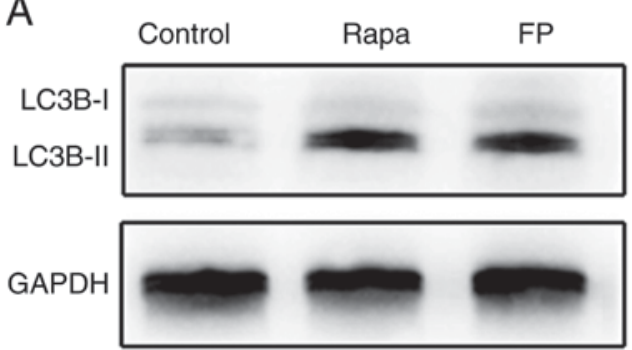

B

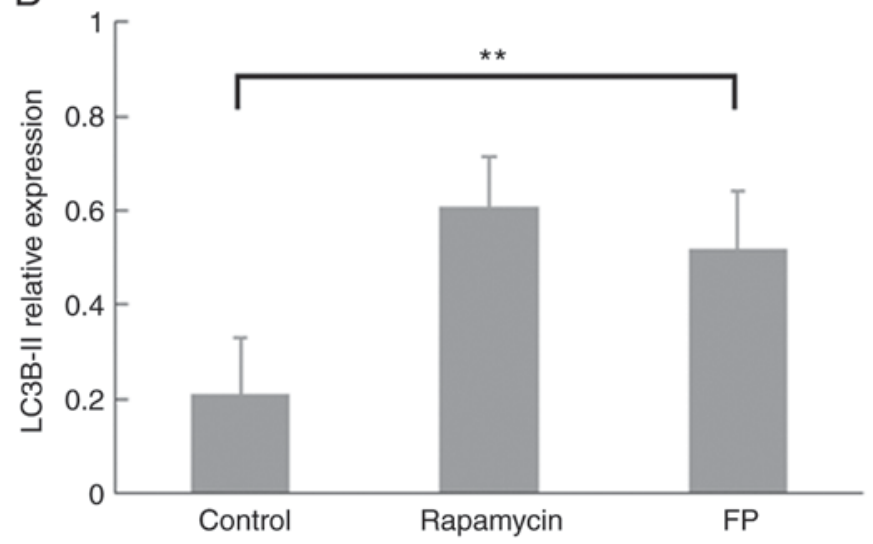

Figure 1. Autophagy induction in MCF-7 cells treated with FP. (A) Immunoblot for LC3B-I and LC3B-II expression in untreated control MCF-7 cells and in cells treated with rapamycin $(5 \mu \mathrm{M})$ or FP $(1 \mu \mathrm{M})$ for $48 \mathrm{~h}$; GAPDH was used as loading control. (B) Densitometric analysis of relative LC3B-II expression in MCF-7 cells; ** $\mathrm{P}<0.01$ vs. control. FP, flavopiridol; LC3B-II, autophagy-related protein LC3B-II; rapa, rapamycin.

A

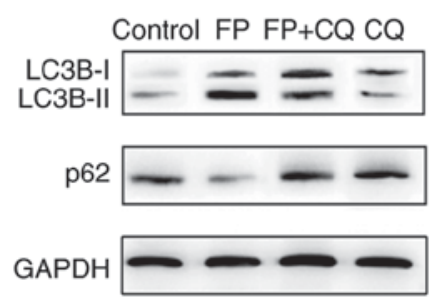

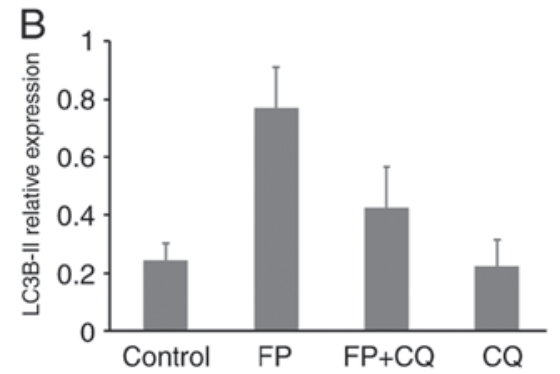

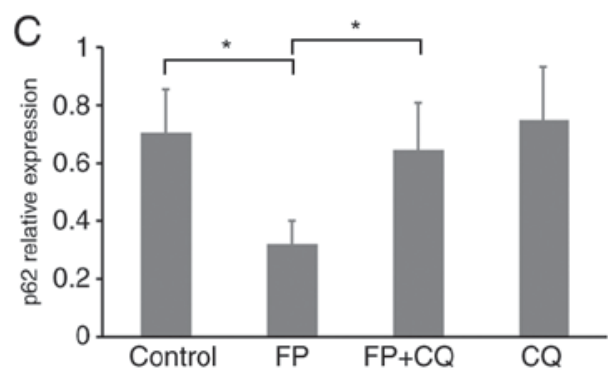

Figure 2. Verification of specific autophagy induced by FP treatment. (A) Immunoblot for LC3B-I and LC3B-II and p62/SQSTM1 expression in MCF-7 cells incubated with FP, FP and CQ co-treatment or CQ alone for $48 \mathrm{~h}$; GAPDH was used as loading control. (B) Densitometric analysis of relative LC3B-II expression in MCF-7 cells. (C) Densitometric analysis of relative p62/SQSTM1 expression in MCF-7 cells; "P<0.05. CQ, chloroquine; FP, flavopiridol; LC3B, autophagy-related protein LC3B; SQSTM1, sequestosome 1.

A

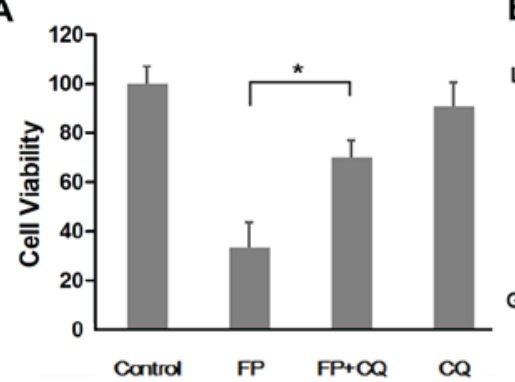

B

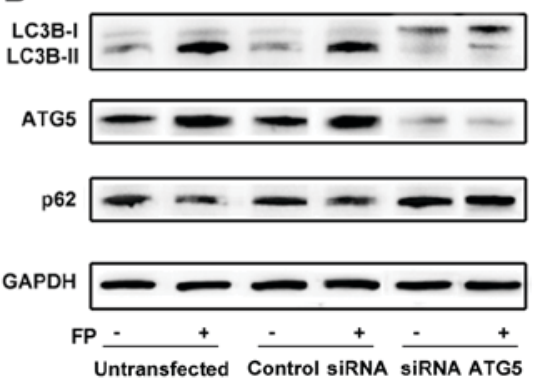

C

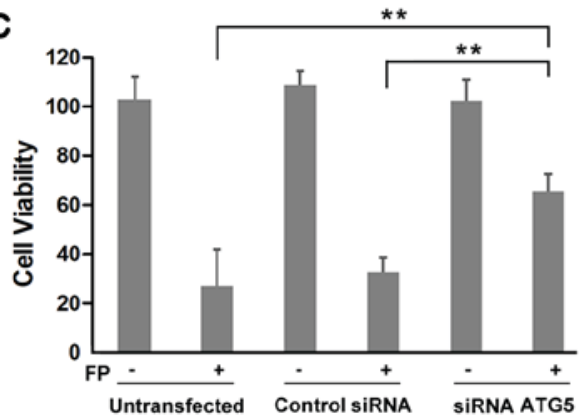

Figure 3. Inhibition of FP-induced autophagy in MCF-7 cells. (A) Viability of MCF-7 cells treated with FP and/or CQ. Viability was significantly decreased with FP treatment compared with FP + CQ co-treatment. (B) Protein expression levels of ATG5, LC3B-I/II and p62/SQSTM1 following siRNA treatment. (C) Viability of MCF-7 cells in untransfected, control siRNA-transfected and ATG5-siRNA groups with or without FP. Viability was significantly higher in cells treated with ATG5 siRNA and FP compared with the untransfected cells and cells transfected with control siRNA cells. "P<0.05, ${ }^{* *} \mathrm{P}<0.01 . \mathrm{CQ}$, chloroquine; FP, flavopiridol; LC3B, autophagy-related protein LC3B; SQSTM1, sequestosome 1.

silencing. Autophagy inhibition did not impair the effects on cell cycle arrest in FP-treated MCF-7 cells.

As autophagy has been considered to be paradoxical in character when MCF-7 cells were treated with different drugs: One involves augmenting proapoptotic autophagy to induce cell death (30), and the other involves the upregulation of pro-survival drug resistance (31). These inconsistent results from previously published work may attribute to the complex role of autophagy in cancer and it is likely dependent on tumor type, stage, and genetic context (32). Further clarification of autophagy may result in new strategies for cancer therapy. Antiapoptotic Bcl-2 protein expression leads to oncogenic transformation and drug resistance in many human cancers, including breast cancer $(33,34)$. $\mathrm{Bcl}-2$ suppresses autophagy by directly binding the $\mathrm{BH} 3$ domain in beclin 1, which is part of a class III PI3K complex that participates in autophagosome formation (35). A previous study using 
MCF-7 cells demonstrated that the Bcl-2/beclin 1 complex may function as a rheostat that ensures that the levels of autophagy remain within a homeostatic rather than a nonphysiological range that triggers cell death (36). Chemotherapeutics may alter $\mathrm{Bcl}-2 /$ beclin 1 binding activity or $\mathrm{Bcl}-2$ expression to regulate autophagy and apoptosis in the cancer cells. These two Bcl-2 regulations may cause different results of cancer cell survival. Inhibition of $\mathrm{Bcl}-2 /$ beclin 1 binding activity may not affect the antiapoptotic function of Bcl-2. Such as Pseudolaric acid $\mathrm{B}$ (PAB), which has been demonstrated to exert an antitumor effect in MCF-7 cells. PAB treatment inhibits the formation of the $\mathrm{Bcl}-2 /$ beclin 1 complex, leaving beclin 1 free to participate in autophagy. However, PAB may also increase Bcl-2 expression and it was concluded that PAB-activated autophagy in MCF-7 cells may contribute to resistance to cell death (37). On the other hand, if Bcl-2 expression was decreased; both autophagy and apoptosis were enhanced. FP has been reported to downregulate the Bcl-2 expression in several types of human breast cancer cell lines (4), which may explain why FP is useful as a medication for cancer therapy. Altogether, the present results demonstrated that FP exposure induced autophagy in MCF-7 human breast cancer cells and autophagy, considering FP as a potential autophagy regulatory molecule for cancer therapy, but further experimentation is required.

\section{Acknowledgements}

This work was supported by The National Natural Science Foundation of China (grant no. 81601535).

\section{References}

1. Howell A, Anderson AS, Clarke RB, Duffy SW, Evans DG Garcia-Closas M, Gescher AJ, Key TJ, Saxton JM and Harvie MN: Risk determination and prevention of breast cancer. Breast Cancer Res 16: 446, 2014.

2. Austreid E, Lonning PE and Eikesdal HP: The emergence of targeted drugs in breast cancer to prevent resistance to endocrine treatment and chemotherapy. Expert Opin Pharmacother 15: 681-700, 2014.

3. Asghar U, Witkiewicz AK, Turner NC and Knudsen ES: The history and future of targeting cyclin-dependent kinases in cancer therapy. Nat Rev Drug Discov 14: 130-146, 2015.

4. DiPippo AJ, Patel NK and Barnett CM: Cyclin-dependent kinase inhibitors for the treatment of breast cancer: Past, Present, and Future. Pharmacotherapy 36: 652-667, 2016.

5. Senderowicz AM and Sausville EA: Preclinical and clinical development of cyclin-dependent kinase modulators. J Natl Cancer Inst 92: 376-387, 2000.

6. Sedlacek HH: Mechanisms of action of flavopiridol. Crit Rev Oncol Hematol 38: 139-170, 2001.

7. Ravishankar D, Rajora AK, Greco F and Osborn HM: Flavonoids as prospective compounds for anti-cancer therapy. Int J Biochem Cell Biol 45: 2821-2831, 2013.

8. Iyer SP, Mejia J, Rosato AE, Grant $S$ and Rosato RR: Flavopiridol-mediated multiple modulatory effects synergistically increase sensitivity to TRAIL-induced cell death in human leukemia cells. Cancer Res 73 (8 Suppl): S2960, 2013.

9. Ali S, El-Rayes BF, Aranha O, Sarkar FH and Philip PA: Sequence dependent potentiation of gemcitabine by flavopiridol in human breast cancer cells. Breast Cancer Res Treat 90: 25-31, 2005.

10. Wittmann S, Bali P, Donapaty S, Nimmanapalli R, Guo F, Yamaguchi H, Huang M, Jove R, Wang HG and Bhalla K: Flavopiridol down-regulates antiapoptotic proteins and sensitizes human breast cancer cells to epothilone B-induced apoptosis Cancer Res 63: 93-99, 2003.

11. Li Y, Bhuiyan M, Alhasan S, Senderowicz AM and Sarkar FH: Induction of apoptosis and inhibition of c-erbB-2 in breast cancer cells by flavopiridol. Clin Cancer Res 6: 223-229, 2000.
12. Klionsky DJ and Emr SD: Autophagy as a regulated pathway of cellular degradation. Science 290: 1717-1721, 2000.

13. Weiner LM and Lotze MT: Tumor-cell death, autophagy, and immunity. N Engl J Med 366: 1156-1158, 2012.

14. Mahoney E, Byrd JC and Johnson AJ: Autophagy and ER stress play an essential role in the mechanism of action and drug resistance of the cyclin-dependent kinase inhibitor flavopiridol. Autophagy 9: 434-435, 2013.

15. Galluzzi L, Pietrocola F, Bravo-San Pedro JM, Amaravadi RK, Baehrecke EH, Cecconi F, Codogno P, Debnath J, Gewirtz DA, Karantza V, et al: Autophagy in malignant transformation and cancer progression. EMBO J 34: 856-880, 2015.

16. Rosenfeldt MT and Ryan KM: The multiple roles of autophagy in cancer. Carcinogenesis 32: 955-963, 2011.

17. Mahoney E, Lucas DM, Gupta SV, Wagner AJ, Herman SE, Smith LL, Yeh YY, Andritsos L, Jones JA, Flynn JM, et al: ER stress and autophagy: New discoveries in the mechanism of action and drug resistance of the cyclin-dependent kinase inhibitor flavopiridol. Blood 120: 1262-1273, 2012.

18. Xie ZZ, Li MM, Deng PF, Wang S, Wang L, Lu XP, Hu LB, Chen Z, Jie HY, Wang YF, et al: Paris saponin-induced autophagy promotes breast cancer cell apoptosis via the Akt/mTOR signaling pathway. Chem Biol Interact 264: 1-9, 2017.

19. Singh A, Chagtoo M, Tiwari S, George N, Chakrabarti B, Khan S, Lakshmi S and Godbole MM: Inhibition of inositol 1,4,5-trisphosphate receptor induce breast cancer cell death through deregulated autophagy and cellular bioenergetics. J Cell Biochem 118: 2333-2346, 2017.

20. Shibata M, Yoshimura K, Furuya N, Koike M, Ueno T, Komatsu M, Arai H, Tanaka K, Kominami E and Uchiyama Y: The MAP1-LC3 conjugation system is involved in lipid droplet formation. Biochem Biophys Res Commun 382: 419-423, 2009.

21. Shibata M, Yoshimura K, Tamura H, Ueno T, Nishimura T, Inoue $\mathrm{T}$, Sasaki M, Koike M, Arai H, Kominami E and Uchiyama Y: LC3, a microtubule-associated protein1A/B light chain3, is involved in cytoplasmic lipid droplet formation. Biochem Biophys Res Commun 393: 274-279, 2010.

22. Klionsky DJ, Abdelmohsen K, Abe A, Abedin MJ, Abeliovich H, Acevedo Arozena A, Adachi H, Adams CM, Adams PD, Adeli K, et al: Guidelines for the Use and Interpretation of Assays for Monitoring Autophagy (3rd edition). Autophagy 12: $1-222,2016$.

23. Ye H, Chen M, Cao F, Huang $\mathrm{H}$, Zhan $\mathrm{R}$ and Zheng $\mathrm{X}$ : Chloroquine, an autophagy inhibitor, potentiates the radiosensitivity of glioma initiating cells by inhibiting autophagy and activating apoptosis. BMC Neurol 16: 178, 2016.

24. Shao X, Gao D, Wang Y, Jin F, Wu Q and Liu H: Application of metabolomics to investigate the antitumor mechanism of flavopiridol in MCF-7 breast cancer cells. J Chromatogr B Analyt Technol Biomed Life Sci 1025: 40-47, 2016.

25. Filippi-Chiela EC, Villodre ES, Zamin LL and Lenz G: Autophagy interplay with apoptosis and cell cycle regulation in the growth inhibiting effect of resveratrol in glioma cells. PLoS One 6: e20849, 2011.

26. Asghar U, Witkiewicz AK, Turner NC and Knudsen ES: The history and future of targeting cyclin-dependent kinases in cancer therapy. Nat Rev Drug Discov 14: 130-146, 2015.

27. Carlson B, Lahusen T, Singh S, Loaiza-Perez A, Worland PJ, Pestell R, Albanese C, Sausville EA and Senderowicz AM: Down-regulation of cyclin D1 by transcriptional repression in MCF-7 human breast carcinoma cells induced by flavopiridol. Cancer Res 59: 4634-4641, 1999.

28. Carlson B, Pearlstein R, Naik R, Sedlacek H, Sausville E and Worland P: Inhibition of CDK2, CDK4 and CDK7 by flavopiridol and structural analogs. Proc Am Assoc Cancer Res 37: 424, 1996.

29. Worland PJ, Kaur G, Stetler-Stevenson M, Sebers S, Sartor O and Sausville EA: Alteration of the phosphorylation state of p34cdc2 kinase by the flavone L86-8275 in breast carcinoma cells: Correlation with decreased H1 kinase activity. Biochem Pharmacol 46: 1831-1840, 1993.

30. Kim DE, Kim Y, Cho DH, Jeong SY, Kim SB, Suh N, Lee JS, Choi EK, Koh JY, Hwang JJ and Kim CS: Raloxifene induces autophagy-dependent cell death in breast cancer cells via the activation of AMP-activated protein kinase. Mol Cells 38, 138-144, 2015.

31. Sun WL, Chen J, Wang YP and Zheng H: Autophagy protects breast cancer cells from epirubicin-induced apoptosis and facilitates epirubicin-resistance development. Autophagy 7: 1035-1044, 2011. 
32. Kimmelman AC: The dynamic nature of autophagy in cancer Genes Dev 25: 1999-2010, 2011.

33. Akkoç Y, Berrak Ö, Arısan ED, Obakan P, Coker-Gürkan A and Palavan-Ünsal N: Inhiition of PI3K signaling triggered apoptotic potential of curcumin which is hindered by Bcl-2 through activation of autophagy in MCF-7 cells. Biomed Pharmacother 71: 161-171, 2015.

34. Kelly PN and Strasser A: The role of Bcl-2 and its pro-survival relatives in tumourigenesis and cancer therapy. Cell Death Differ 18: 1414-1424, 2011.

35. Liang XH, Kleeman LK, Jiang HH, Gordon G, Goldman JE, Berry G, Herman B and Levine B: Protection against fatal Sindbis virus encephalitis by beclin, a novel Bcl-2-interacting protein. J Virol 72: 8586-8596, 1998.
36. Pattingre S, Tassa A, Qu X, Garuti R, Liang XH, Mizushima N, Packer M, Schneider MD and Levine B: Bcl-2 antiapoptotic proteins inhibit Beclin 1-dependent autophagy. Cell 122: 927-939, 2005.

37. Yu J, Chen C, Xu T, Yan M, Xue B, Wang Y, Liu C, Zhong T, Wang Z, Meng X, et al: Pseudolaric acid B activates autophagy in MCF 7 human breast cancer cells to prevent cell death. Oncol Lett 11: 1731-1737, 2016. 